\title{
Design and Tests
}

\section{of the pHEMT GaAs MIC Input Switch-off LNA of Own Production for Equipment of Autonomous Spacecraft Radionavigation}

\author{
Vadim N. Shkolniy a, Sergey B. Suntsova, \\ Aleksey V. Kondratenkob ${ }^{b}$, Dmitriy A. Shishkin ${ }^{b}$, \\ Kirill A. Alekseev ${ }^{b}$ and Vadim M. Karaban*b

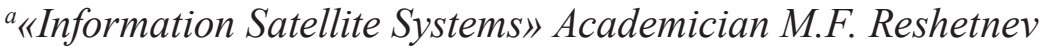 \\ 52 Lenin Str., Zheleznogorsk, \\ Krasnoyarsk region, 662972, Russia \\ ${ }^{6}$ Tomsk State University \\ of Control Systems and Radioelectronics \\ 40 Lenin Str., Tomsk, 634050, Russia
}

The presents of design and experimental tests results of electrical characteristics of monolithic integrated circuit of the input switch-off low-noise amplifier based on pHEMT GaAs-technology of own production for use in the on-board navigation receivers of global navigation satellite systems signals for autonomous coordinate and time support of all types orbits spacecraft.

Keywords: semiconductors, nanoheterostructures, arsenide-gallium technology, monolithic integrated circuits, spacecraft, autonomous navigation, on-off switch, low noise amplifier.

Citation: Shkolniy V.N., Suntsov S.B., Kondratenko A.V., Shishkin D.A., Alekseev K.A., Karaban V.M. Design and tests of the pHEMT GaAs MIC input switch-off LNA of own production for equipment of autonomous spacecraft radionavigation, J. Sib. Fed. Univ. Eng. technol., 2016, 9(2), 204-213, DOI: 10.17516/1999-494X-2016-9-2-204-213.

(C) Siberian Federal University. All rights reserved

* Corresponding author E-mail address: karaban_vm@mail.ru 


\title{
Проектирование и испытания рНЕМТ GaAs МИС коммутируемого по входу МШУ \\ собственного производства
}

\section{для аппаратуры автономной радионавигации КА}

\author{
В.Н. Школьныйа \\ Д.А. Шишкин ${ }^{\tilde{\sigma}}$ К.А. Алексеев ${ }^{\tilde{\sigma}}$, В.М. Карабан \\ ${ }^{a} A O$ «Информационные спутниковые системы»» \\ им. академика М.Ф. Решетнёва» \\ Россия, 662972, Красноярский край, \\ Железногорск, ул. Ленина, 52 \\ ${ }^{6}$ Томский государственный университет \\ систем управления и радиоэлектроники \\ Россия, 634050, Томск, пр. Ленина, 40
}

\footnotetext{
Представлены результаты проектирования и натурных испытаний электрических характеристик монолитно-интегральной схемы (МИС) коммутируемого по входу малошумящего усилителя на основе рНЕМТ арсенид-галлиевой технологии собственного производства для применения в составе бортовых навигаџионных приёмников сигналов глобальных навигационных спутниковых систем космических аппаратов всех типов орбит для их автономного координатно-временного обеспечения.
}

Ключевые слова: полупроводники, наногетероструктуры, арсенид-галлиевая технология, монолитные интегральные схемы, космический аппарат, автономная навигация, двухпозиционный коммутатор, маломумящий усилитель.

\section{Введение}

Координатно-временное обеспечение является одним из важнейших условий успешного функционирования космических аппаратов различного назначения, в особенности тех, полезная нагрузка которых представляет собой измерительные системы: активные и пассивные радиолокаторы, средства наблюдения и дистанционного зондирования, навигационные устройства и др. Особое значение координатно-временное обеспечение имеет в случаях совместного функционирования нескольких космических аппаратов, которые решают общую задачу.

Для функционирования на разных типах орбит (низких, геостационарных, высокоэллиптических) необходимо использовать несколько антенн (антенно-фидерных систем), которые посредством коммутатора подключаются к приёмнику сигналов глобальных навигационных спутниковых систем (ГНСС). К тому же коммутатор выполняет ещё и функцию защиты входных цепей приёмника от электростатических разрядов.

Малошумящий усилитель (МШУ) в приёмном тракте выполняет первый этап усиления слабого принятого сигнала. От его линейности, шумовых и усилительных свойств зависят итоговые характеристики всего приёмника [1].

В данной статье рассматривается разработка МИС совмещённого устройства: коммутируемого по входу МШУ, выполняющего одновременно функции подключения антенн

$$
-205-
$$


(антенно-фидерных систем) и усиления слабого принятого сигнала для применения в составе многоканальных ГНСC приёмников L-диапазона частот на основе pHEMT арсенид-галлиевой технологии собственного производства.

Ближайший зарубежный аналог GaAs MИC двухпозиционного коммутатора HMC190AMS8 производства компании Hittite Microwave (США) [2]. Ближайший отечественный аналог GaAs МИС двухпозиционного коммутатора МР202 производства ЗАО «НПФ «Микран» (г. Томск) [3].

Ближайший зарубежный аналог GaAs MИC МШУ HMC618LP3 производства компании Hittite Microwave (США) [4]. Ближайший отечественный аналог GaAs MИС МШУ MP502 производства ЗАО «НПФ «Микран» (г. Томск) [5].

К разработке рHЕMT GaAs МИС коммутируемого по входу МШУ TSR060 (ТУСУР) предъявлены следующие технические требования: границы рабочей частоты 1,1-1,7 ГГц; коэффициент усиления не менее 16 дБ; коэффициент шума (NF) не более 2,5 дБ; выходная мощность при сжатии на 1 дБ не менее 10 дБм; напряжение питания МШУ 5 В; управляющее напряжение коммутатора $0 \ldots .5 \mathrm{~B}$; ток потребления не более 80 мА.

\section{Проектирование МИС}

Схема коммутатора МИС коммутируемого по входу МШУ TSR060 (ТУСУР) разработана на нормально открытых полевых транзисторах с затвором Шоттки [6-8]. В режиме коммутируемого сопротивления канала коммутатор является двухполюсным элементом, поэтому для него также справедливо введение понятия качества [9-10] с целью определения предельных значений вносимого затухания и развязки. При проектировании МИС на полевых транзисторах с затвором Шоттки определяющими параметрами коммутатора являются удельные паразитные сопротивления и ёмкости на единицу ширины затвора транзистора. Паразитные сопротивления и ёмкости зависят от исходного полупроводникового материала, из которого изготавливается транзистор, а также от его топологии и технологии производства [11].

Одно из основных требований к транзисторам в схеме коммутатора - это низкий уровень вносимых потерь в открытом состоянии. Для достижения этого необходимо уменьшать паразитное сопротивление в цепи исток - сток.

Разработка МШУ МИС коммутируемого по входу МШУ TSR060 (ТУСУР) проводилась согласно методике совмещённого согласования [12-14]. МШУ содержит один каскад на полевых транзисторах с высокой подвижностью электронов (pHЕМТ) с интегрированными цепями согласования, коррекции амплитудно-частотной характеристики, а также ввода и блокировки питания. Выбор параллельной резистивной обратной связи в каскаде обусловлен требованиями обеспечения равномерного коэффициента усиления в рабочем диапазоне частот, а также согласования выхода МИС с трактом СВЧ. Для организации требуемого режима по постоянному току в каскаде используется схема автосмещения.

Электрическая принципиальная схема и топология МИС коммутируемого по входу МШУ TSR060 (ТУСУР) приведена на рис. 1 и 2: IN1, IN2 - вход СВЧ-сигнала 1 и 2; OUT - выход CBЧ-сигнала; VD - напряжение питания усилителя; VSS - опорное напряжение коммутатора; VSA - напряжение питания схемы стабилизации напряжения смещения усилителя; VG - на- 


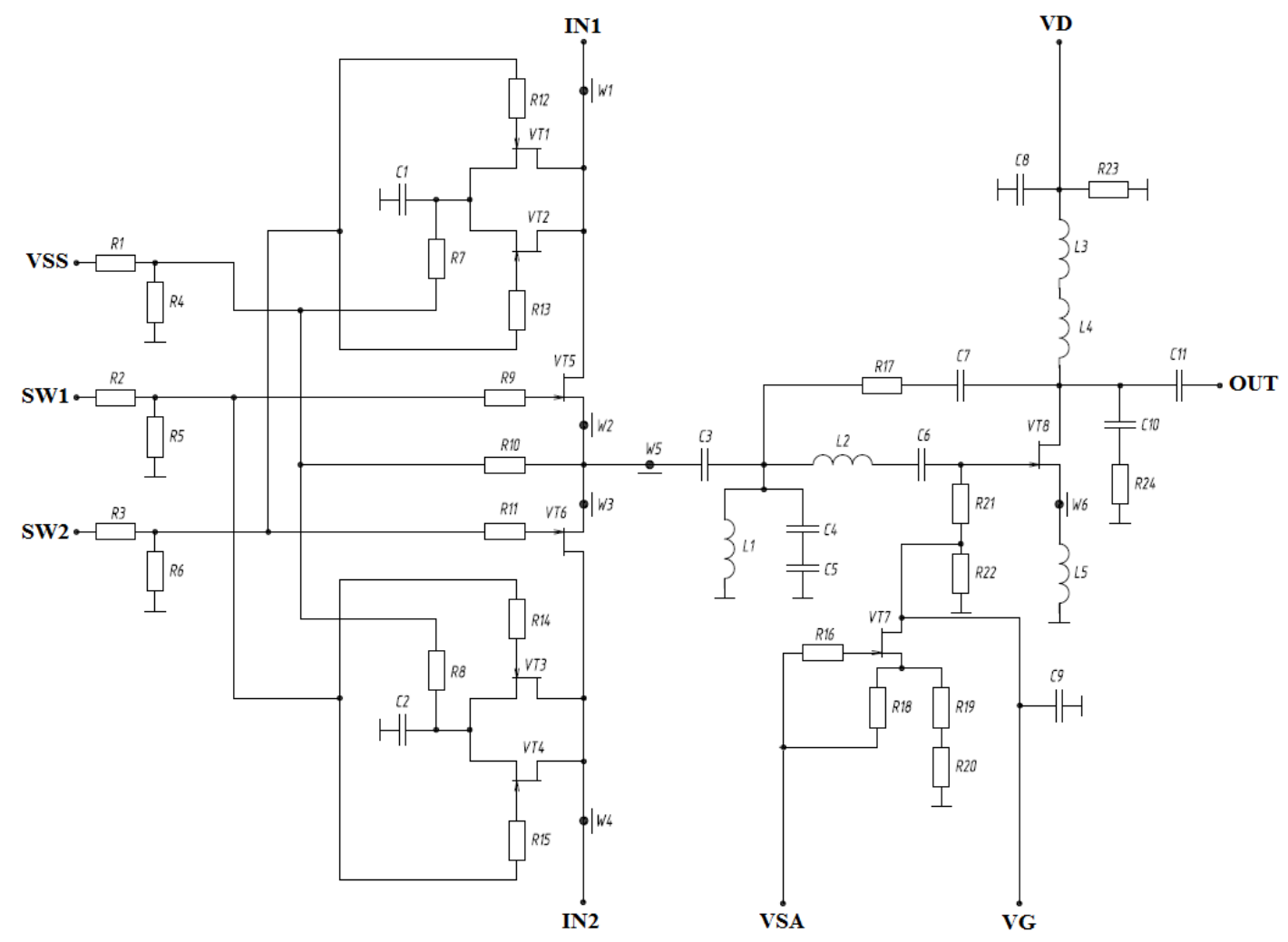

Рис. 1. Схема электрическая pHEMT GaAs МИС коммутируемого МШУ TSR060 (ТУСУР)

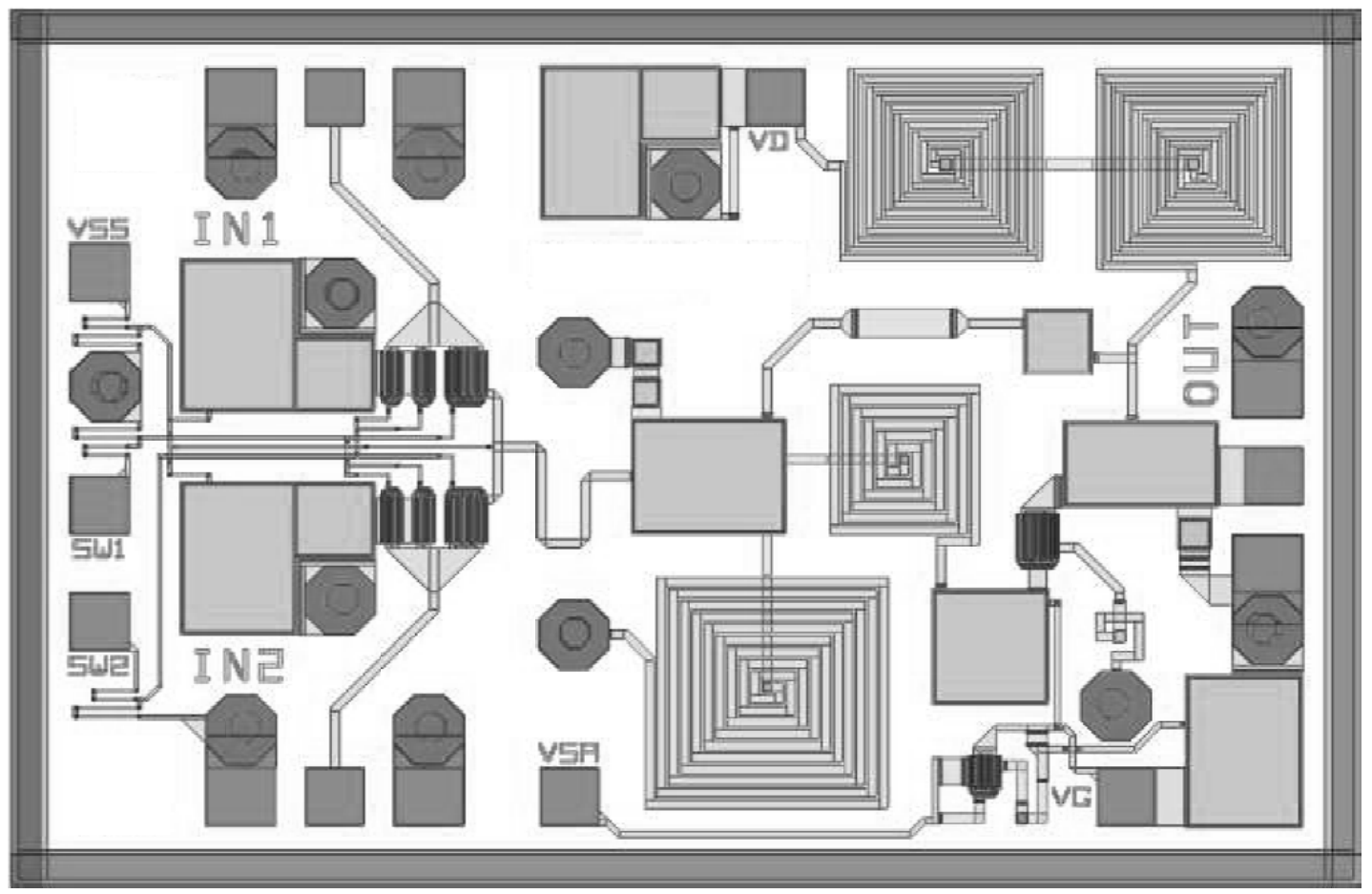

Рис. 2. Схема электрическая pHEMT GaAs МИС коммутируемого МШУ TSR060 (ТУСУP) 
пряжение смещения усилителя; SW1, SW2 - напряжение управления коммутатором 1 и 2 . На рис. 3 представлены результаты моделирования частотных характеристик.

\section{Электрические испытания МИС}

Общим условием при проведении натурных испытаний стало то, что измерение электрических характеристик кристаллов МИС проводилось непосредственно на полупроводниковой пластине с помощью зондовой станции Suss Micro Tec 200m (рис. 4). Двухканальный источник питания Agilent E3646А служит для установки режима по постоянному току объекта испытаний.

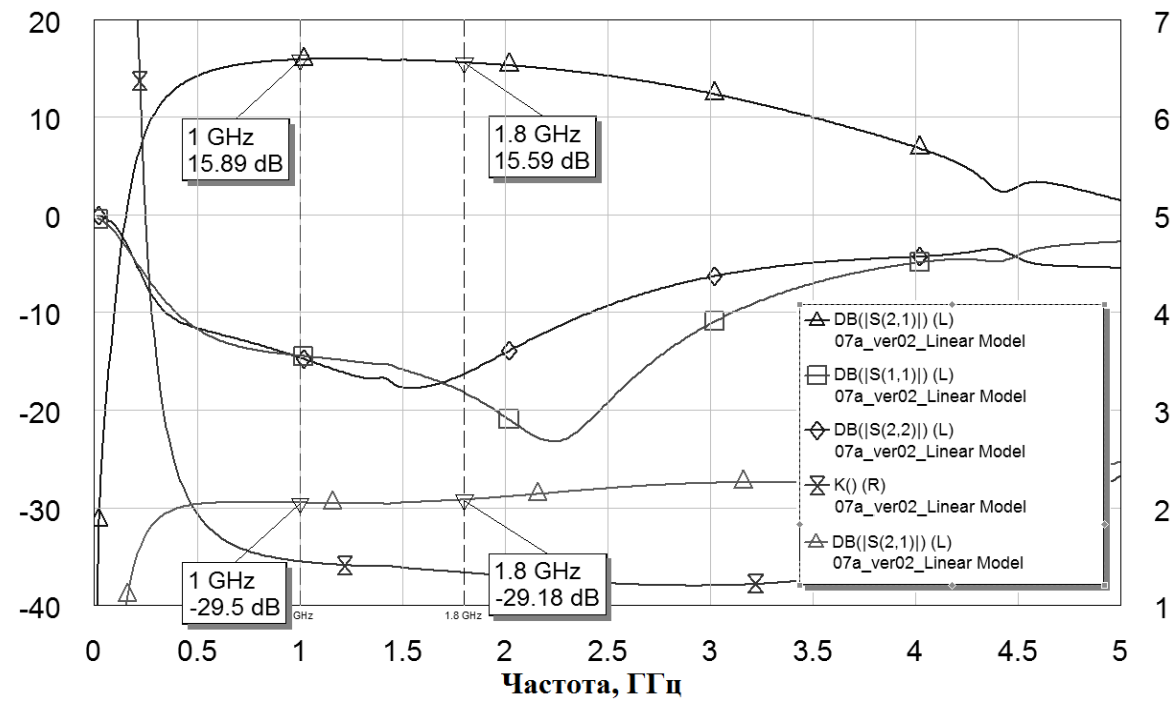

$a$

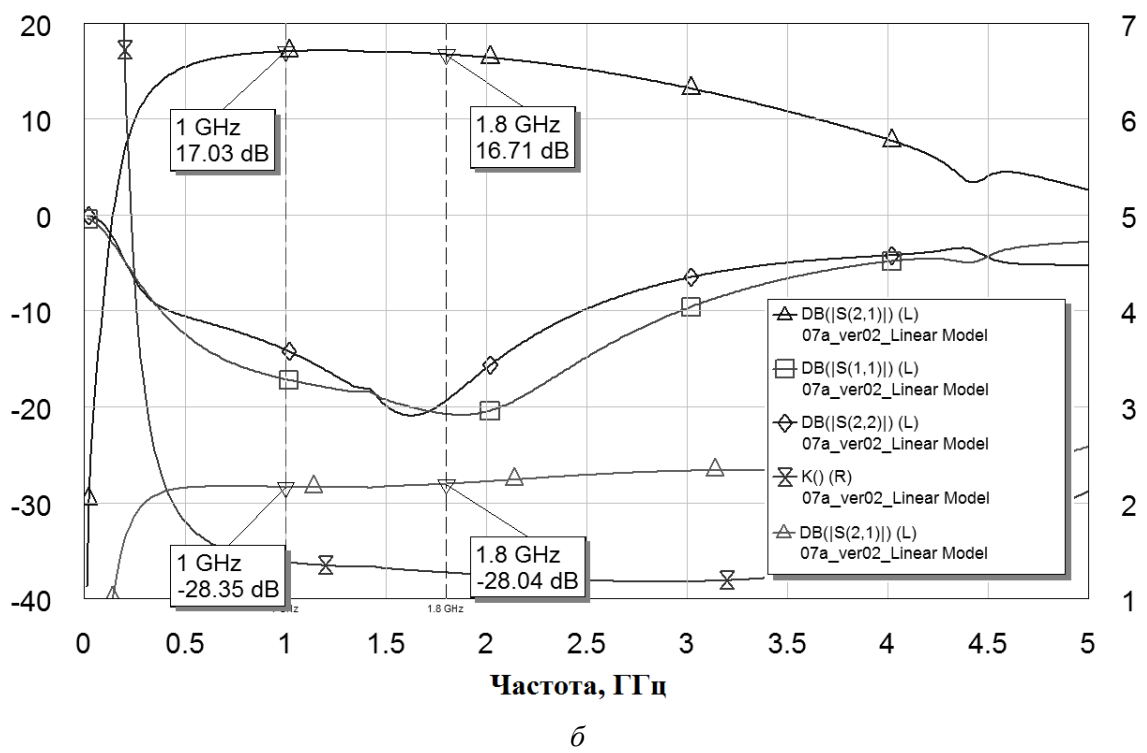

Рис. 3. Расчётные S-параметры pHEMT GaAs МИС коммутируемого МШУ TSR060 (TUSUR): VSA=минус 5 (а) и VSA=0 (б) 


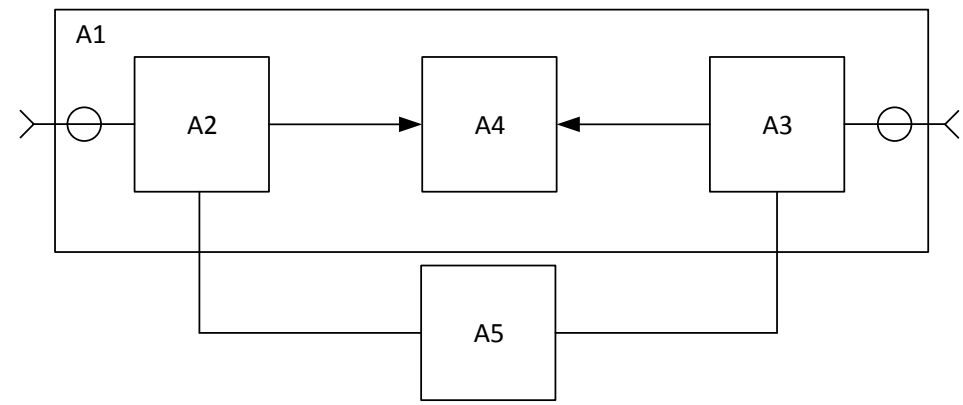

Рис. 4. Схема подключения объекта испытаний: A1 - зондовая станция Suss Micro Tec 200m; A2, A3 - СВЧ-зонды Z040-K3N-GSG-150; A4 - объект испытаний; A5 - источник питания Agilent E3646A

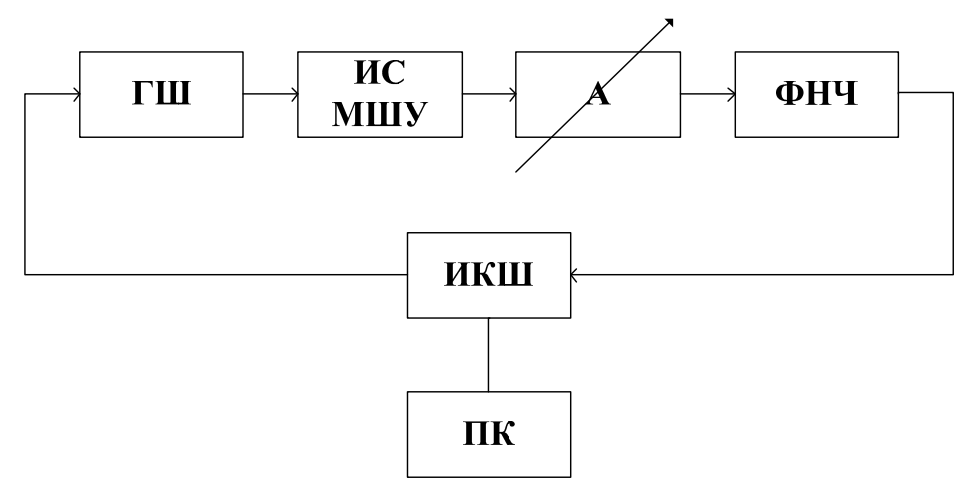

Рис. 5. Схема измерения коэффициента шума: ГШ - генератор шума; А - переменный аттенюатор; ПК - персональный компьютер; ИКШ - измеритель коэффициента шума

В основу измерения коэффициента шума положен метод Y-фактора, прямыми измерениями которого являются измерения мощности. Для проведения измерений коэффициента шума используется измеритель коэффициента шума Agilent N8975A, который позволяет проводить измерения в диапазоне от 10 МГц до 26 ГГц. Погрешность измерения в диапазоне частот $\leq 3$ ГГц не превышает 0,05 дБ. Измерение коэффициента шума отображается блоксхемой на рис. 5.

Полное измерение коэффициента шума в данном случае состоит из двух шагов. Первый шаг называется калибровкой, которая производится без измеряемого устройства. На вход измерителя коэффициента шума подключается генератор шума (ГШ) с калиброванным значением избыточного коэффициента шума (ENR). В нашем случае использовался ГШ фирмы Agilent $\mathrm{N} 4001 \mathrm{~A}$, основанный на эффекте возникновения шумового сигнала при лавинном пробое $\mathrm{p}-\mathrm{n}$ перехода диода, имеющий ENR от 4,5 до 6,0 дБ. При калибровке в прибор вводят таблицу ENR в точках частотного диапазона согласно маркировке ГШ. Для прибора Agilent N8975A эта операция производится автоматически, без участия оператора.

При проведении калибровки измеряют Ү-фактор, который определяется как отношение выходной мощности шума при включенном («On») и выключенном («Off») состоянии ГШ, а также шумовых температур, соответствующих данным режимам. Используя соотношение

$$
-209-
$$




$$
\text { F }=\text { ENR / (Y-1) }
$$

И

$$
\mathrm{ENR}=10 \lg \left[\left(\mathrm{T}_{1}-\mathrm{T}_{2}\right) / \mathrm{T}_{0}\right]
$$

где $\mathrm{T}_{1}$ - шумовая температура при включенном ГШ; $\mathrm{T}_{2}$ - шумовая температура при выключенном ГШ; $\mathrm{T}_{0}=290 \mathrm{~K}$ - опорная шумовая температура, определяется коэффициент шума прибора. В конце калибровки прибор сохраняет измеренные значения и приводит кривые изменения коэффициента шума к номинальному значению 0 дБ. После этого прибор готов к измерению электрических характеристик МИС коммутируемого по входу МШУ.

Следующим шагом после калибровки является включение измеряемого устройства в разрыв между генератором шума и прибором и проводится повторное измерение коэффициента шума методом Ү-фактора. При этом коэффициент шума испытуемой МИС определяется из условия

$$
\mathrm{F}_{1}=\mathrm{F}_{\mathrm{S}}-\left(\mathrm{F}_{2}-1\right) / \mathrm{Kp}
$$

где $\mathrm{F}_{1}$ - коэффициент шума МИС; $\mathrm{F}_{\mathrm{S}}$ - коэффициент шума системы, состоящей из каскадного соединения МИС и прибора; $\mathrm{F}_{2}$ - коэффициент шума прибора; Кр - коэффициент усиления МИС.

Представленный метод измерения позволяет с высокой точностью определять коэффициент шума в широком частотном диапазоне. При этом результаты измерения выводятся на экран прибора в виде численных значений и панорамных графиков.

Результаты измерения показали, что коэффициент шума имеет значение 2,2 дБ, что в 2 раза превосходит отечественный аналог $(4,5$ дБ), но также в 2 раза уступает зарубежному $(0,85$ 1,1 дБ). Это в первую очередь связано с технологией изготовления [10], которая рассчитана на большую мощность.

Измерение амплитудно-частотной характеристики (АЧХ) коэффициента передачи (|S21|), а также нижней и верхней частот диапазона рабочих частот МИС проводится с помощью векторного анализатора цепей Agilent N5242AS (рис. 6).

Анализатор цепей Agilent N5242AS позволяет проводить измерение S-параметров в частотном диапазоне от 10 МГц до 26,5 ГГц. Для испытания требуемых параметров МИС коммутируемого по входу МШУ TSR060 (TUSUR) на пластине анализатор цепей Agilent N5242AS подключается в качестве измерительного прибора к зондовой станции (см. рис. 4).

Перед проведением измерений, как и для измерения коэффициента шума, осуществляется калибровка прибора с устранением влияния зондовой станции. Кроме того, методы калибровки предполагают коррекцию ошибок рассогласования на входе и выходе при измерениях параметров передачи, что значительно уменьшает неравномерность частотной характеристики и улучшает точность измерения, которая для коэффициента передачи $\leq 0,047$ дБ.

Проведённые измерения зависимостей АЧХ коэффициента передачи опытных образцов МИС МШУ TSR060 (ТУСУР) показали изменение величины коэффициента передачи в пределах 23-25 дБ, что существенно превосходит как отечественный (18-20 дБ), так и зарубежный (19 дБ) показатели. Частотный диапазон составил от 1,0 (нижняя граничная частота) до 2,5 ГГц 


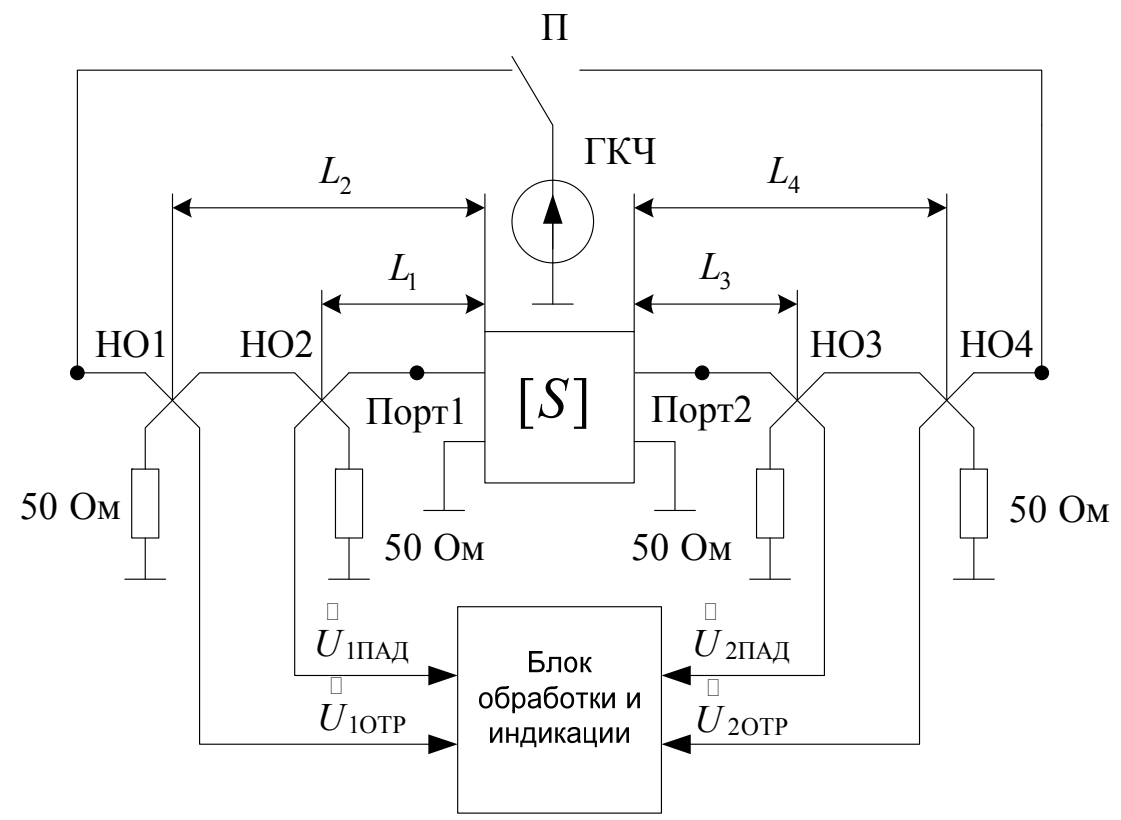

Рис. 6. Структурная схема векторного анализатора цепей Agilent N5242AS: ГКЧ - генератор качающейся частоты

(верхняя граничная частота) при значениях рассматриваемых аналогов: MP502 - от 1 до 4 ГГц, HMC618LP3 - от 1,2 до 1,7 ГГц.

Выходную мощность по критерию сжатия коэффициента передачи на 1 дБ измеряли на следующем оборудовании: в качестве СВЧ-генератора был использован СВЧ-выход анализатора цепей Agilent N5242AS, который имеет при выходной мощности 0 дБмВт очень низкий уровень гармонических составляющих (минус 60 дБ); СВЧ-усилитель MAHW-020200 фирмы «Микран» служит для развязки и раскачки выходного сигнала генератора.

Измерение выходной мощности производится СВЧ-ваттметром Agilent N1911A, работающем в частотном диапазоне от 50 МГц до 18 ГГц. Пределы измерения выходной мощности от $0,3^{*} 10^{-7}$ Вт до 0,1 Вт при относительной погрешности $\pm 5 \%$.

В начале измерения устанавливается относительно малый уровень входного воздействия (минус 40 дБмВт) и определяется малосигнальный коэффициент передачи по мощности:

$$
\mathrm{K}_{\mathrm{P}}\left(\text { (Д) }=10 \cdot \lg \left(\mathrm{P}_{\mathrm{BbX}} / \mathrm{P}_{\mathrm{BX}}\right) .\right.
$$

По мере увеличения выходной мощности за счёт нелинейных эффектов происходит уменьшение (сжатие) коэффициента передачи. Линейным считается режим, при котором сжатие коэффициента передачи не превышает 1 дБ.

Для МИС коммутируемого по входу МШУ TSR060 (ТУСУР) по отмеченной методике был определен уровень выходной мощности, соответствующий снижению К рый составил 17 дБм во всём частотном диапазоне. Данная величина немногим превосходит соответствующий показатель для отечественного (13,5 дБм) и зарубежного (14,5-10,0 дБм) аналогов. 
Ток потребления, который фиксировался источником питания Agilent E3646A, находился в диапазоне 67-71 мА при соответствующем показателе MP502 в 80 мА и HMC618LP3 в 11865 мА.

\section{Заключение}

Таким образом, результаты натурных испытаний показали, что разработанные схемотехнические и топологические решения экспериментального образца МИС коммутируемого по входу МШУ (TSR060) L-диапазона частот на основе собственной (НОЦ «Нанотехнологии» ТУСУР) 0,15 мкм рНЕМТ GaAs-технологии обладают параметрами на уровне современных аналогов и пригодны для применения в составе ГНСС-приёмников, а также прочих радиотехнических устройств и систем космического назначения.

Работа выполнена в НОЦ «Нанотехнологии» ТУСУР в рамках реализации постановления Правительства РФ от 09.04.2010 г. № 218 и договора между ОАО «ИСС» И Минобрнауки РФ от 12.02.2013 2. № 02.G 25.31.0042 [15].

\section{Список литературы}

[1] Дмитриев В.Д., Терешков В.В., Саяпин В.Ю. и др. Доклады ТУСУР, 2014, 3(33), 16-21 [Dmitriev V.D., Tereshkov V.V., Saiapin V.Iu. et. al. The layout of the multichannel receiver unit of the system of Autonomous navigation. Doklady TUSUR, 2014, 3(33), 16-21 (in Russian)]

[2] HMC190AMS8/190AMS8E - GaAs MMIC SPDT Switch DC-3 Ghz [Электронный ресурс]. Режим доступа: http://www.radiant.su/other/hittite/pdf/hmc190ams8.pdf, свободный (дата обращения: 10.06.2013).

[3] GaAs MИС двухпозиционного СВЧ коммутатора MP202 [Электронный ресурс]. - Peжим доступа: http://www.micran.ru/productions/MIS/switches/MP202, свободный (дата обращения: 10.06.2013).

[4] HMC618LP3/618LP3E - GaAs SMT pHEMT Low Noise Amplifier, 1.2 - 2.2 GHz [Электронный ресурс]. - Режим доступа: http://www.radiant.su/other/hittite/pdf/hmc618lp3.pdf, свободный (дата обращения: 10.06.2013).

[5] GaAs МИС широкополосного усилителя 1-4 ГГи MP502 [Электронный ресурс]. - Режим доступа: http://www.micran.ru/productions/MIS/amplifiers/MP502, свободный (дата обращения: 10.06.2013).

[6] Петрова Т.С., Ерёмина Е.Л., Игнатьев М.Г. и др. Монолитная интегральная схема двухпозиционного СВЧ-коммутатора на GaAs. Известия Томского политехнического университеma, 2006, 309(8), 172-175 [Petrova T.S., Eremina E.L., Ignatiev M.G. et. al. Monolithic integrated circuit two-position microwave switch on GaAs. Bulletin of the Tomsk Polytechnic University, 2006, 309(8), 172-175 (in Russian)]

[7] Баров А.А., Гюнтер В.Я., Игнатьев М.Г., Петрова Т.С. Управляющие монолитноинтегральные схемы СВЧ на базе GaAs ПТШ. 15-я Международная Крымская конференция «СВЧ-техника и телекоммуникационные технологии» (КрыМиКо'2005). Материалы конференции (Севастополь, 12-16 сентября 2005 г.). Севастополь: Вебер, 2005, с.175-176 [Barov A.A., Gunter V.Ia., Ignatiev M.G., Petrova T.S. Control of monolithic integrated circuits of microwave GaAs 
MESFET. 15th international Crimean conference "Microwave equipment and telecommunication technologies". Sevastopol', Veber, 2005, p.175-176 (in Russian)]

[8] Полевые транзисторы на арсениде галлия. Принципы работы и технология изготовления. Пер. с англ. под ред. Д. В. Ди Лоренцо, Д. Д. Канделуола. М.: Радио и связь, 1988, 496 с. [Field effect transistors on gallium arsenide. Di Lorenzo D.V. (ed.)]

[9] Gutmann R.J., Fryklund D.J. Characterization of Linear and Nonlinear Properties of GaAs MESFET's for Broad-Band Control Applications. Transactions on Microwave Theory and Techniques, 1987, 35(5), 516-521.

[10]Зыков Д.Д., Матвеев В.В., Нечаев К.А., Карабан В.М. Повышение качества продукции посредством использования причинно-следственной диаграммы в комплексе с информационной системой управления полупроводниковым производством. Доклады ТУСУР, 2013, 4(30), 173-176 [Zykov D.D., Matveev V.V., Nechaev K.A., Karaban V.M. Improving product quality through the use of causal diagrams in combination with management information system for semiconductor manufacture. Doklady TUSUR, 2013, 4(30), 173-176 (in Russian)]

[11] Jain N., Gutmann R.J. Modeling and Design of GaAs MESFET Control Devices for BroadBand Applications. Transactions on Microwave Theory and Techniques, 1990, 38(2), 109-117.

[12]Мокеров В.Г., Бабак Л.И., Фёдоров Ю.В. и др. Разработка комплекта монолитных малошумящих усилителей Х-диапазона на основе 0,15 мкм GaAs pHEMT-технологии. Доклады ТУСУРа, 2010, 2(22), 105-117 [Mokerov V.G., Babak L.I., Atljhjd Iu.V. et. al. Development of a set of monolithic low noise amplifiers X-band based on a $0.15 \mu \mathrm{m}$ GaAs pHEMT technology. Doklady TUSUR, 2010, 2(22), 105-117 (in Russian)]

[13] Арыков В.С., Баров А.А., Кондратенко А.В. GaAs pHEMТ МИС малошумящего усилителя Х-диапазона Сб. трудов 21-й Междунар. Крымской конф. «СВЧ-техника и телекоммуникационные технологии». Севастополь: Вебер, 2011, 1, 159-160 [Arykov V.S., Barov A.A., Kondratenko A.V. MIS GaAs pHEMT low noise amplifier X-band. 21th international Crimean conference "Microwave equipment and telecommunication technologies". Sevastopol', Veber, 2011, 1, 159-160 (in Russian)]

[14]Текшев В.Б. Двухтранзисторный СВЧ-усилитель с минимальным коэффициентом шума и согласованным входом и выходом. Общие вопросы радиоэлектроники, 1990, 15, 16-23 [Tekeshev V.B. Dvukhchastotnyi microwave amplifier with minimum noise figure and the agreed entry and exit. Obshchie voprosy radioelektroniki, , 1990, 15, 16-23 (in Russian)]

[15] Куприц В.Ю., Шарыгин Г.С., Школьный В.Н. Повышение помехоустойчивости автономной системы навигации космических аппаратов. Доклады ТУСУР, 2014, 3(33), 22-26 [Кuprits V.Iu., Sharygin G.S.,Shkolnii V.N. Increased robustness of Autonomous navigation of space vehicles. Doklady TUSUR, 2014, 3(33), 22-26 (in Russian)] 